\title{
Kan Bağıșını Etkileyen Faktörlerin Belirlenmesine Yönelik Bir Araştırma
}

\author{
Fuat YALMAN ${ }^{1}$, Yalçın KARAGÖZ 國 ${ }^{1}$
}

ÖZ

Amaç: Bu araştırmada kan bağışında bulunmada etkili olan faktörlerin belirlenmesi amaçlanmıştır.

Gereç ve Yöntemler: Araştırmanın evrenini Samsun il merkezinde ikamet eden ve sağlık hizmetlerini kullanan genç, orta ve ileri yaş grubu bireyler oluşturmaktadır. Araştırmanın örneklemi ise 400 katılımcıdan oluşmaktadır. Araştırmada kolayda örnekleme yöntemi kullanılmıştır. Veriler online (internet üzerinden anket tekniği) anket tekniği ile toplanmıştır. Verilerin analizinde SPSS 26 ve AMOS 24 paket programları kullanılmıştır. Araştırmada açıklayıcı faktör analizi ve doğrulayıcı faktör analizi teknikleri kullanılmıştır.

Bulgular: Katılımcılara 37 maddeden oluşan taslak ölçek uygulanmış ve elde edilen veriler analiz edilmiştir. Verilere öncelikle açıklayıcı faktör analizi uygulanmıştır. Bu aşamada hiçbir faktör altında toplanmayan 11 madde ölçekten çıkarılmış ve sonuçta 26 maddeyi içeren 5 faktör bulunmuştur. Daha sonra belirlenen faktörlere doğrulayıcı faktör analizi uygulanmıştır. Elde edilen modelin verilere mükemmel uyum gösterdiği belirlenmiştir. Dolayısıyla, açıklayıcı faktör analizi ile geliştirilen tutum ölçeğinin geçerliliği doğrulayıcı faktör analizi ile de teyit edilmiştir. Ölçeğin Cronbach $\alpha$ katsayısı ise 0,945 olarak hesaplanmış ve oldukça güvenilir olduğu sonucuna varılmıştır. Bunun yanı sıra katılımcıların kan bağışında bulunmada etkili olan faktörlere ilişkin düşüncelerinin yaş ve meslek gruplarına göre anlamlı farklılık gösterip göstermediğini belirlemek amacıyla yapılan ANOVA analizi sonuçlarına göre; yaşın ve mesleğin tüm alt gruplarına göre verilen cevaplarda anlamlı farklılık olduğu gözlemlenmiştir.

Sonuç: Geliştirilen ölçeğin, kan bağışında bulunmada etkili olan faktörlerin belirlenmesine yönelik bireylerin tutumlarını ölçmek için, geçerli ve güvenilir bir araç olduğu sonucuna varılmıştır.

Anahtar Kelimeler: Kan bağışı; doğrulayıcı faktör analizi; yapısal eşitlik modellemesi

\section{A Research to Determine the Factors Affecting Blood Donation}

\section{ABSTRACT}

Aim: In this study, it was aimed to determine the factors that are effective in donating blood.

Material and Methods: The universe of the research consists of young, middle and elderly individuals who live in Samsun city center and use health services. The sample of the study consists of 400 participants. The convenience sampling method was used in the study. The data were collected by the online (online survey technique) survey technique. The total number of questionnaires evaluated and used in data analysis is 400. SPSS 26 and AMOS 24 package programs were used in the analysis of the data. Explanatory factor analysis and confirmatory factor analysis techniques were used in the study.

Results: The draft scale which is consisted of 37 items is applied on participants and the data obtained is analysed. First, exploratory factor analysis is conducted on data. At this stage, 11 items, which are found not to load on any factor, are removed from the scale and eventually 5 factors including 26 items are formed. Subsequently, confirmatory factor analysis is conducted with the determined factors. It is concluded that there is a good fit between measurement model and the observed data. As a result, the validity of the scale developed by using exploratory factor analysis is confirmed with confirmatory factor analysis. Also, Cronbach $\alpha$ coefficient of the scale is found to be 0,945 and therefore it is concluded that the scale is quite reliable. In addition, according to the results of the ANOVA analysis, it was determined that the participants' opinions about the factors that affect blood donation differ significantly according to age and all subgroups of the profession.

Conclusion: It was concluded that the developed scale was a valid and reliable tool to measure the attitudes of 
individuals towards determining the factors that affect donating blood.

Keywords: Blood donation; confirmatory factor analysis; structural equation modeling

\section{GIRIŞ}

Kan naklinin hayat kurtardığı ve sağlığı iyileştirdiğ bilinmektedir ancak transfüzyona ihtiyaç duyan birçok hastanın güvenli kana zamanında erişiminin sağlanamadığı da rastlanan bir durumdur. Güvenli ve yeterli kan sağlamak, her ülkenin ulusal sağlık politikasının ve altyapısının ayrılmaz bir parçası olmalıdır (1). Yüksek gelirli ülkelerde, transfüzyon için başlıca endikasyonlar; karmaşık tıbbi ve cerrahi prosedürler, maligniteler ve travmalardır. Hamilelik komplikasyonları ve çocukluk çağı anemisi ise, orta ve düşük gelirli ülkelerde büyük ölçüde kan nakline ihtiyaç duyulan durumlardır. Güvenli kana erişim sağlanarak

anne ölümlerinin dörtte birinden fazlasının önlenebildiği görülmüştür (2). Günümüzde tıp alanında yaşanan bilimsel ve teknolojik gelişmelere rağmen, hala insan kanının ve kan bileşenlerinin yerine geçebilecek herhangi bir tedavi aracı bulunamamıştır ve mevcut tek seçenek kan bağışıdır (3). Kan, alternatifi olmayan karmaşık bir sıvıdır. Bu nedenle insanlar; kan bağışı, kan ve kan bileşenlerinin tek kaynağı olmaya devam edeceklerdir. Bir birim kan miktarı; paketlenmiş hücre hacmine, taze donmuş plazmaya, trombosit konsantresine ve kriyopresipitat ve granülosit konsantresine dönüştürülebilir. Böylelikle tek bir ünite kan, birden fazla hastaya fayda sağlayabilir (4).

Her üç saniyede bir birey, kan transfüzyonuna ihtiyaç duymaktadır. Hem kentsel hem de kırsal alanda, sürekli kan transfüzyonu ihtiyacı ortaya çıkmaktadır. Geçmişte gerektiği durumlarda kanın tedarik edilememesinden dolayı, çok sayıda vaka mortalite ve morbidite ile sonuçlanmıştır (4). Ülkemizde her geçen gün önemli sayıda hasta zamanında tedavileri için kan bağışı yapacak insanları beklemekteyken; birçok kişi de, bunun aksine zamanında kan temin edilememesi dolayısıyla hayatlarını kaybetmektedir (5). Kan bağışı sadece alıcıya fayda sağlamakla kalmaz, aynı zamanda vericinin de sağlığını da iyileştirir, vücuttaki demir seviyelerini dengeler, pıhtılaşmayı azaltarak kan akışını düzenler, fazla kaloriyi yakar ve kolesterol seviyesini düşürür (31). Yapılan çalışmalarda; düzenli kan bağışçılarının, donör olmayanlara kıyasla kalp krizi geçirme olasılığının \%88 daha az olduğu, daha uzun ömürlü olduğu ve kalp hastalığı, hipertansiyon, diyabet, hiper kolesterolemi ve embolik atak geliştirme riskinin daha düşük olduğu bulunmuştur (6).

Dünya Sağl1k Örgütü, nüfusun \%1'inin kan bağış1 yapmasının genellikle bir ülkenin en temel kan gereksinimlerini karşılamak için gereken minimum miktar olduğunu tahmin etmektedir. Aynı zamanda Dünya Sağlık Örgütü (WHO) kan bağışının gönüllü ve ücretsiz hale gelmesini teşvik etmektedir (7). Yeterli ve güvenilir bir kan tedarikinin, fedakârlık veya sosyal sorumluluk tarafından motive edildikleri ve kişisel tatmin ve öz saygı ile ödüllendirildikleri için; düzenli, gönüllü, ücretsiz kan bağışçılarından oluşan istikrarlı bir temel ile sağlanabildiği belirtilmiştir. Doğru bir iletişim ise, başarılı ve sürdürülebilir bir gönüllü kan bağışı programının merkezinde yer alır. Gençler, sağlıklı ve hevesli oldukları için dünyadaki güvenli kan tedarikinin umudu ve geleceği olarak görülmektedir (8).

İnsanları kan bağışı yapmaya motive eden temel faktörleri belirlemek için çok sayıda araştırma yapılmıştır $(9,10)$. Bunun yanı sıra kan bağışçılarının, cinsiyet, yaş, medeni durum, etnik köken, eğitim düzeyleri ve gelir düzeyi gibi sosyo-ekonomik ve demografik özelliklerine göre bağışçı olmayanlardan nasıl farklılaştığını incelemek için de çalışmalar yapılmıştır (11). Başka bir araştırmada, kan bağışı sürecine ilişkin bilgi birikimi ve kan ihtiyacı arttıkça, kan bağışı yapma olasılığının da arttığı gözlemlenmiştir (12). Diğer taraftan daha önceki kan bağışı deneyimi, önceki bağışların sayısı ve son bağışın süresi, gelecekteki davranışın tahmin edilmesiyle ilişkilendirilmiştir (13). Diğer taraftan kan bağışını etkileyen faktörler tam olarak anlaşılmamış ve ülkeden ülkeye değişebilse de, Çin ve diğer ülkelerde yapılan çoğu çalışmada fedakarlık veya başkalarına yardım kan bağışının ana nedeni olarak rapor edilmiştir (14-16). Kan bağışı için bildirilen diğer nedenler arasında ise karş1lıklılık, samimi hırs, suçluluk ve teşvik olarak nitelendirilmiştir (17-18). Aynı zamanda önceki kan bağışı programlarına katılmaktan elde edilen tatmin edici bir deneyim, tekrarlanan bağışları etkileyen temel faktör olarak görülmüștür (19).

Sonuç olarak yeterli miktarda kan tedarikinin sağlanabilmesi için, toplama merkezlerinin, aktif bir donör havuzunu oluşturması ve sürdürülebilir kampanyalar tasarlaması gerektiği vurgulanmıştır. Bireyleri bağış yapmaya motive eden veya bağış yapmaktan caydıran faktörleri anlamak, merkezlerin amaçladıkları takviye kampanyaları geliştirmesine yardımcı olabilir (20). Kan bağışçısı motivasyonu üzerine yapılan araştırmalar çok fazla olmasına rağmen, çoğu çalışma tipik olarak küçük değişkenler kümesine odaklanmış, eşdeğer yapıları etiketlemek için farklı terminoloji kullanmış ve bulguları kendi bireysel ortamlarının ötesine geçememiştir. Dolayısıyla kan bağışı konusunda doğru bilgi sahibi olunması hayati önem taşımaktadır. Tıp literatüründe kan ihtiyacı ve kan bağışı konularında çok sayıda araştırma yapılmış olmasına rağmen Türkiye ölçeğinde sınırlı sayıda çalışma mevcuttur. Toplumun kan, kan gereksinimi ve kan bağışı konusunda neleri, ne kadar ve ne derece doğru bildiğinin tespit edilmesi bir gerekliliktir. Tüm bunlar göz önüne alındığında topluma yönelik kan bağışını etkileyen faktörleri ölçmeye yarayan bir ölçek geliştirmenin ve bu sayede toplumun farkındalıklarının artmasını sağlamanın yararlı olacağı düşünülmektedir. $\mathrm{Bu}$ araştırmada kan bağışını etkileyen faktörleri ölçmeye yarayan bir ölçeğin geliştirilmesi amaçlanmıştır.

\section{GEREÇ VE YÖNTEMLER}

Araştırmanın Etik Yönü: $\mathrm{Bu}$ araştırma, Düzce Üniversitesi Bilimsel Araştırma ve Yayın Etik Kurulu'ndan etik onayı alınarak gerçekleştirilmiştir (Tarih: 27.08.2020, karar no: 2020/172).

\section{Araştırmanın Evren ve Örneklemi}

Araştırmanın evrenini Samsun il merkezinde ikamet eden ve sağlık hizmetlerini kullanan genç, orta ve ileri yaş grubu kişiler oluşturmaktadır. Araştırmanın örneklemini ise kolayda örnekleme yöntemi ile ulaşılmış, 400 
katılımcı oluşturmaktadır. Nüfusu 496000 olan Samsun ilinde örnekleme yapılmıştır. Bu konuyla ilgili daha önceki çalışmalardan, standart sapma 0,6 ve yanılma payı 0,0588 olarak belirlenmiştir. Yapılan çalışmada 0,05 anlamlılık düzeyinde örneklem hacmi; $\mathrm{N}=496000$, $=0,05, \quad=0,51, \quad=1,96,=0,0588$ değerlerinden faydalanılarak,

$\mathrm{n}=\frac{\mathrm{N} \cdot \sigma^{2} \cdot \mathrm{Z}_{\alpha / 2}^{2}}{\mathrm{~d}^{2}(\mathrm{~N}-1)+\sigma^{2} \cdot \mathrm{Z}_{\alpha / 2}^{2}}=\frac{496000 \cdot(0,6)^{2} \cdot(1,96)^{2}}{(0,0588)^{2}(5000-1)+(0,6)^{2} \cdot(1,96)^{2}} \cong 400$ bulunmuştur.

\section{Araştırmanın Kavramsal Modeli}

Kan bağışında bulunmada etkili olan faktörler ile bu faktörler arasındaki yapısal ilişkilerin tespit edilmesi kapsamında araştırmanın kavramsal modeli tasarlanmıştır. Araştırmanın kavramsal modeli, araştırmanın temel değişkenleri kan bağışında bulunmada etkili olan faktörler (toplumsal ve sosyal sorumluluk, toplumsal görüş ve anlayış, toplum üzerinde etkili kişilerin rolü, davranışsal inançlar ve sağlık açısından faydalı olması) arasındaki yapısal ilişkileri tartışmaktadır.

\section{Veri Toplama Yöntemi ve Ölçeğin Olușturulması}

Verilerin elde edilmesi için internet üzerinden anket tekniği kullanılmıştır. Çalışmanın anket hazırlanırken detaylı literatür taraması yapılmış, alandan uzmanlar ile görüşülmüş ve kavramsal çerçeve oluşturulmuştur. Madde havuzu her olasılığın yakalanabilmesine imkan verecek şekilde geniş olması gerektiğinden, 40 maddelik taslak ölçek oluşturulmuştur. Taslak ölçek için Halk Sağlığı ve Sağlık Yönetimi alanında öğretim üyesi olan 6 uzmandan uzman görüşü alınmıştır. Uzman görüşleri doğrultusunda 3 madde çıkarılarak 37 maddelik taslak ölçek oluşturulmuştur. Ölçek maddeleri 1- Kesinlikle Katılmiyorum, 2- Katılmiyorum, 3- Ne Katıliyorum Ne Katılmiyorum, 4- Katıliyorum, 5- Kesinlikle Katılıyorum şeklinde derecelendirilmiştir. Uzman görüşleri sonucunda taslak ölçeğin kapsam geçerlik indeksi 0,86 olarak hesaplanmıştır. Anket formu, iki bölümden oluşmaktadır. Birinci bölümde katılımcıların demografik özellikleri ile düzenli bir şekilde kan bağışında bulunup bulunmama durumu, herhangi bir kronik hastalığın olup olmaması durumu ve düzenli ilaç kullanıp kullanmama durumunu tanımlayan ifadeler yer alırken, ikinci bölümde kan bağışında bulunmada etkili olan faktörleri belirlemeye yönelik ifadeler yer almaktadır.

\section{Araştırmada Kullanılan Ölçekler}

Kan bağışında bulunmada etkili olan faktörleri belirlemek için kullanılan ölçek formu gerekli literatür taraması sonucunda Çelik ve Güven (2015)'in kan bağışı tutum ölçeği ile Wiwanitkit (2002) ve Alam ve Masalmeh (2004)'in çalışmalarından faydalanılarak araştırmacı tarafından uyarlanmıştır $(12,21,23)$.

\section{İstatistiksel Analiz}

Araştırma kapsamında toplanan veriler SPSS 26 ve AMOS 24 istatistiksel analiz programlarına yüklenmiş ve analiz edilmiştir. Yürütülen araştırmanın amacına ve veri toplama yöntemine bağlı olarak veri analizinde, açıklayıcı ve doğrulayıcı faktör analizi teknikleri kullanılmıştır. Farklılık analizleri için de $\mathrm{t}$ testi ve ANOVA testi kullanılmıştır.

Değişkenlerin yer aldıkları faktördeki yük değerleri için alt sınır 0.40 kabul edilmiştir. Birden fazla faktör altında toplanan ve faktör yükleri arasındaki farkın 0.10'dan düşük olduğu maddeler ise binişik madde olarak tanımlanmış ve ölçekten çıkarılmıştır. Özgün değeri 1'in üstünde olan faktörler önemli faktör olarak kabul edilmiştir. Faktörlerin bağımsızlığını, yorumlamada açıklık ve anlamlılığını sağlamak amacıyla rotasyon yapılmıştır. Rotasyon tekniği olarak dik döndürme tekniği kullanılmıştır. Açıklanan varyans oranı olarak ise \%55 sınır değer olarak kabul edilmiştir. Faktörlerin bağımsızlığını, yorumlamada açıklık ve anlamlılı̆̆ını sağlamak amacıyla rotasyon yapılmıştır. Rotasyon tekniği olarak dik döndürme tekniği kullanılmıştır.

Her bir yapı üzerindeki gözlenen değişkenlerin standartlaştırılmış yüklemelerinin, anlamlı ve üstün yakınsak geçerliliğin 0.5 'ten yüksek olup olmadığ kontrol edilmiştir. Daha sonra geçerliliği kontrol etmek için bileşik güvenilirlik (CR) testi yapılmıştır. Her bir yapı için çıkarılan ortalama varyansın, diğer yapılarla paylaşılan varyansından daha büyük olması durumunda ayırt edici geçerliliğin sağlandığı durumu kontrol edilmiştir.

\section{BULGULAR}

Araştırma Verilerinin Güvenilirliği ve Pilot Çalışma

Kavramsal yapının (çerçeve) oluşturulması; Madde havuzunun oluşturulması için ilgili literatür taranmış ve ölçülecek olgunun kavramsal çerçevesi (yapısı) kapsamlı bir biçimde oluşturulmuştur.

Madde havuzunun oluşturulması; Literatürde bulunan daha önce geliştirilmiş ölçekler incelenmiş, cevaplayıcı kitlesine açık uçlu sorular sorulmuş ve ilgili uzmanların görüşleri alınarak madde havuzu oluşturulmuştur. "Kan Bağışı ölçeğini”" geliştirmek için madde havuzunda, beşli Likert ölçeğine göre 40 madde oluşturulmuştur.

Havuzdaki maddelerin uzman görüşüne sunulması; İncelenecek olguyla ilgili ciddi bilgi alt yapısına sahip 6 uzman, havuzdaki her bir maddeyi incelemiş ve kavramsal çerçeve göz önüne alınarak maddelerin 3 tanesinin ölçekten çıkarılmasına karar vermiştir.

Pilot çalışmanın yapılması; Taslak ölçekle 20 kişi üzerinde pilot çalışma yapılarak maddelerdeki ifade hataları, cevaplayanlar tarafindan yanlış anlaşııı durumları, yazım hataları, imla hataları vb. hatalar düzeltilmiştir.

Test yeniden test güvenilirliğinin yapılması; Test yeniden test güvenilirliği için taslak ölçek 30 kişiye 2 haftalık zaman aralığıyla, iki defa uygulanmış ve ölçekten alınan toplam puanlar aşağıda verilmiştir. Birinci ve ikinci uygulama arasındaki Pearson korelasyon katsayısının düzeyi (derecesi) 0,868'dir (\%86,8). Yani, birinci ve ikinci uygulama arasında çok kuvvetli (çok yüksek) pozitif korelasyon vardır. Bulunan korelasyon katsayısı, aynı zamanda kararlılık katsayısıdır. Yani, kararlılık katsayısı $\rho=0,868$ 'dir. Kararlılık katsayısının çok yüksek olması, farklı zamanlarda yapılan ölçümlerin çok benzer olduğunu göstermektedir. Bu durum da ölçeğin, oldukça kararlı bir ölçek olduğunu göstermektedir. Kararlılık aynı zamanda bir güvenilirlik göstergesi olduğundan, ölçek yüksek derecede güvenilirdir.

Hedef kitleye taslak ölçeğin uygulanması; 400 kişiye yüz yüze anket uygulanmıştır.

İç tutarlılık güvenilirliği için madde analizinin yapılması; Güvenilirlik analizi için hedef kitleden elde edilen 
verilere, "Madde-toplam korelasyonuna dayalı madde analizi" yapılmış ve bütün maddelerin uyum sağladığı görülerek 37 madde ile analize devam edilmiştir. 37 madde için yapılan güvenilirlik katsayısı Alfa=0,945'tür. $\mathrm{Bu}$ değer $0,80 \leq \alpha<1,00$ arasında olduğundan, ölçek yüksek derecede güvenilirdir.

\section{Demografik Bulgular}

Araştırmaya katılan bireylerin \%65'ini kadın, \%35'ini erkek katılımcılar oluştururken; \%42'sini orta yaş gurubu (36-45 arası) katılımcılar oluşturmakta, \%47'sini özel sektör çalışanı oluşturmaktadır. Katılımcıların \%42'si son bir y1l içerisinde en az 2-3 defa hastaneye gittiklerini, \%76'sı bir sağlık problemi yaşadıklarında ilk olarak devlet hastanesine başvurduklarını, \%91'i herhangi bir kronik hastalığının olmadığını, \%81'i düzenli kullandıkları bir ilacın olmadığını ve \%44'ü düzenli bir şekilde kan bağışında bulunmadıklarını belirtmişlerdir.

\section{Açıklayıcı Faktör Analizine İlişkin Bulgular}

Katılımcıların kan bağışında bulunmaya yönelik davranışlarını oluşturan verilere açıklayıcı faktör analizi uygulanmıştır. $\mathrm{Bu}$ doğrultuda gerçekleştirilen analiz aşağıda Tablo 1'de yer almaktadır.

Tablo 1. Kan bağışında bulunma-açıklayıcı faktör analizi sonuçları

\begin{tabular}{|c|c|c|c|c|}
\hline Faktörler & $\begin{array}{c}\text { Değişkenl } \\
\text { er }\end{array}$ & $\begin{array}{l}\text { Faktör } \\
\text { Yükleri }\end{array}$ & $\begin{array}{c}\text { Açılanan } \\
\text { Varyans }\end{array}$ & Öz Değer \\
\hline \multirow{8}{*}{$\begin{array}{l}\text { Toplumsal ve } \\
\text { Sosyal } \\
\text { Sorumluluk } \\
\text { (Faktör1) }\end{array}$} & Madde 30 & 0,774 & \multirow{8}{*}{34,827} & \multirow{8}{*}{9,055} \\
\hline & Madde29 & 0,721 & & \\
\hline & Madde 32 & 0,713 & & \\
\hline & Madde35 & 0,703 & & \\
\hline & Madde26 & 0,679 & & \\
\hline & Madde27 & 0,665 & & \\
\hline & Madde31 & 0,634 & & \\
\hline & Madde34 & 0,634 & & \\
\hline \multirow{6}{*}{$\begin{array}{l}\text { Toplumsal } \\
\text { Görüş ve } \\
\text { Anlayış } \\
\text { (Faktör2) }\end{array}$} & Madde18 & 0,718 & \multirow{6}{*}{10,916} & \multirow{6}{*}{2,838} \\
\hline & Madde20 & 0,704 & & \\
\hline & Madde22 & 0,688 & & \\
\hline & Madde19 & 0,688 & & \\
\hline & Madde17 & 0,535 & & \\
\hline & Madde23 & 0,493 & & \\
\hline \multirow{5}{*}{$\begin{array}{l}\text { Toplum } \\
\text { Üzerinde Etkili } \\
\text { Kişilerin Rolü } \\
\text { (Faktör3) }\end{array}$} & Madde9 & 0,774 & \multirow{5}{*}{6,334} & \multirow{5}{*}{1,647} \\
\hline & Madde10 & 0,712 & & \\
\hline & Madde6 & 0,711 & & \\
\hline & Madde8 & 0,701 & & \\
\hline & Madde5 & 0,635 & & \\
\hline \multirow{4}{*}{$\begin{array}{l}\text { Davranışsal } \\
\text { İnançlar } \\
\text { (Faktör4) }\end{array}$} & Madde14 & 0,800 & \multirow{4}{*}{4,761} & \multirow{4}{*}{1,238} \\
\hline & Madde15 & 0,754 & & \\
\hline & Madde37 & 0,717 & & \\
\hline & Madde13 & 0,712 & & \\
\hline \multirow{3}{*}{$\begin{array}{l}\text { Sağlık } \\
\text { Açısından } \\
\text { Faydalı Olması } \\
\text { (Faktör5) }\end{array}$} & Madde2 & 0,761 & \multirow{3}{*}{4,485} & \multirow{3}{*}{1,166} \\
\hline & Madde1 & 0,737 & & \\
\hline & Madde3 & 0,616 & & \\
\hline $\begin{array}{l}\text { Değerlendirme } \\
\text { Kriterleri }\end{array}$ & \multicolumn{4}{|c|}{$\begin{array}{l}\text { Kaiser-Meyer-Olkin Measure of Sampling } \\
0,902 \\
\text { Approx. Chi-Square: } 5229,476 \\
\text { Barlett's Test of Sphericity: } 0,000 \\
\text { Extraction Method: Principal Components } \\
\text { Rotation Method: Varimax } \\
\text { Açılanan Varyans Toplamı: } 61,323\end{array}$} \\
\hline
\end{tabular}

Kan bağışında bulunmada etkili olan faktörlerin alt değişkenlerini belirlemek amacıyla faktör analizine tabi tutulan veriler için $\mathrm{p}(\mathrm{sig})=0,000<0,05$ olduğundan Bartlett testinin sonucu anlamlıdır. Yani, değişkenler arasında yüksek korelasyonlar mevcuttur ve veriler çoklu normal dağılımdan gelmiş demektir. KMO katsayısı 0,902 olduğundan sonuç mükemmeldir. $\mathrm{Bu}$ sebeple, araştırmada örnek büyüklüğü yeterlidir.

\section{Farklılık Analizlerine İlişkin Bulgular}

Araştırmanın bu bölümünde kan bağışıında bulunmada etkili olan faktörlerin, araştırmaya katılan bireylerin demografik özelliklerine göre, farklı şekilde algılanıp algılanmadığını belirlemek amacıyla farklılık testleri (ttesti ve ANOVA) yapılmıştır ve Tablo 2'de sunulmuştur. Katılımcıların kan bağışında bulunmada etkili olan faktörlere ilişkin düşüncelerinin, cinsiyet gruplarına göre anlamlı farklılık gösterip göstermediğini belirlemek amacıyla yapılan t-testi sonuçlarına göre; Faktör 2toplumsal görüş ve anlayış ( $\mathrm{t}$ testi $=2,360 ; \mathrm{p}<00,5)$ ile Faktör 4-davranışsal inançlar ( $\mathrm{t}$ testi $=2,222 ; \mathrm{p}<0,05$ ) boyutları için cinsiyetin alt gruplarına göre verilen cevaplarda anlamlı farklılık olduğu; bunun aksine "Faktör 1-toplumsal ve sosyal sorumluluk", "Faktör 3-toplum üzerinde etkili kişilerin rolü" ve "Faktör 5-sağlık açısından faydalı olması" boyutları için cinsiyetin alt gruplarına göre verilen cevaplarda anlamlı farklılık olmadığı görülmüştür.

Katılımcıların kan bağışında bulunmada etkili olan faktörlere ilişkin düşüncelerinin yaş gruplarına göre anlamlı farklılık gösterip göstermediğini belirlemek amaciyla yapılan ANOVA testi sonuçlarına göre; Faktör $1(\mathrm{~F}=3,953 ; \mathrm{p}<0,05)$, Faktör $2(\mathrm{~F}=9,678 ; \mathrm{p}<0,05)$, Faktör $3(\mathrm{~F}=2,892 ; \mathrm{p}<0,05)$, Faktör $4(\mathrm{~F}=8,343 ; \mathrm{p}<0,05)$ ve Faktör $5 \quad(\mathrm{~F}=3,243 ; \mathrm{p}<0,05)$ 'e göre kan bağışında bulunmada etkili olan bütün faktörler için yaşın tüm alt gruplarına göre verilen cevaplarda anlamlı farklılık olduğu gözlemlenmiştir.

Son olarak katılımcıların kan bağışında bulunmada etkili olan faktörlere ilişkin düşüncelerinin mesleklerine göre anlamlı farklılık gösterip göstermediğini belirlemek amacıyla yapılan ANOVA testi sonuçlarına göre; Faktör $1(\mathrm{~F}=2,184 ; \mathrm{p}<0,05)$, Faktör $2(\mathrm{~F}=4,536 ; \mathrm{p}<0,05)$, Faktör $3(\mathrm{~F}=2,479 ; \mathrm{p}<0,05)$ ve Faktör $4(\mathrm{~F}=3,909 ; \mathrm{p}<0,05)$ 'e göre kan bağışında bulunmada etkili olan bütün faktörler için mesleğin alt gruplarına göre verilen cevaplarda da anlamlı farklılık olduğu gözlemlenmiştir.

\section{Doğrulayıcı Faktör Analizi ile İlgili Bulgular}

$\mathrm{Bu}$ bölümde, AMOS paket programı ile kan bağışında bulunmada etkili olan faktörlere, DFA yapılarak verinin varsayılan modele uyum derecesi test edilmiştir.

Araştırma Modeline (Ölçüm Modeli) Ait Sonuçlar Araştırma modelinde yer alan değişkenler; "toplumsal ve sosyal sorumluluk", "toplumsal görüş ve anlayış", "toplum üzerinde etkili kişilerin rolü”, “davranışsal inançlar" ve "sağlık açısından faydalı olması" ile bu faktörler arasındaki nedensel ilişkilerin açıklanabileceği varsayılmıştır. Kullanılan ölçeklerin geçerliliğini test etmek için doğrulayıcı faktör analizi yapılmış ve tüm ölçeklerin yapıları doğrulanmıştır. Şekil 1'de kan bağışında bulunmada etkili olan faktörler ile ilgili doğrulayıcı faktör analizi sonuçları ve uyum iyiliği değerleri verilmiştir. 
Tablo 2. Kan bağışını etkileyen faktörlere ilişkin araştırmaya katılan katılımcıların sosyo-demografik özellikleri $(\mathrm{n}=400)$

\begin{tabular}{|c|c|c|c|c|c|c|c|c|c|c|}
\hline & \multicolumn{2}{|c|}{ Faktör 1} & \multicolumn{2}{|c|}{ Faktör 2} & \multicolumn{2}{|c|}{ Faktör 3} & \multicolumn{2}{|c|}{ Faktör 4} & \multicolumn{2}{|c|}{ Faktör 5} \\
\hline Variables & t Testi/ & $\mathbf{p}$ & t Testi/ & $\mathbf{p}$ & t Testi/ & $\mathbf{p}$ & t Testi/ & $\mathbf{p}$ & t Testi/ & $\mathbf{p}$ \\
\hline Cinsiyet & \multirow{3}{*}{$1,435^{\mathrm{a}}$} & \multirow{3}{*}{0,152} & \multirow{3}{*}{$2,360^{\mathrm{a}}$} & \multirow{3}{*}{0,019} & \multirow{3}{*}{, $168^{\mathrm{a}}$} & \multirow{3}{*}{0,867} & \multirow{3}{*}{2,222} & \multirow{3}{*}{0,027} & \multirow{3}{*}{1,178} & \multirow{3}{*}{0,239} \\
\hline Erkek & & & & & & & & & & \\
\hline Kadın & & & & & & & & & & \\
\hline Yaş & \multirow{6}{*}{$3,953^{\mathrm{b}}$} & \multirow{6}{*}{0,004} & \multirow{6}{*}{$9,678^{b}$} & \multirow{6}{*}{$\mathbf{0 , 0 0 0}$} & \multirow{6}{*}{$2,892^{b}$} & \multirow{6}{*}{0,022} & \multirow{6}{*}{$8,343^{\mathrm{b}}$} & \multirow{6}{*}{0,000} & \multirow{6}{*}{$3,243^{b}$} & \multirow{6}{*}{$\mathbf{0 , 0 1 2}$} \\
\hline $18-25$ & & & & & & & & & & \\
\hline $26-35$ & & & & & & & & & & \\
\hline $36-45$ & & & & & & & & & & \\
\hline $46-55$ & & & & & & & & & & \\
\hline$>55$ & & & & & & & & & & \\
\hline Meslek & \multirow{10}{*}{$2,184^{\mathrm{b}}$} & \multirow{10}{*}{0,028} & \multirow{10}{*}{$4,536^{\mathrm{b}}$} & \multirow{10}{*}{0,000} & \multirow{10}{*}{$2,479^{b}$} & \multirow{10}{*}{0,012} & \multirow{10}{*}{3,909} & \multirow{10}{*}{0,000} & & \\
\hline İşçi & & & & & & & & & & \\
\hline Memur & & & & & & & & & & \\
\hline Emekli & & & & & & & & & & \\
\hline Ev Hanımı & & & & & & & & & 1063 & 0380 \\
\hline Serbest & & & & & & & & & 1,005 & 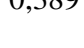 \\
\hline Öğrenci & & & & & & & & & & \\
\hline Özel Sektör & & & & & & & & & & \\
\hline Çalışmıyor & & & & & & & & & & \\
\hline Diğer & & & & & & & & & & \\
\hline
\end{tabular}

Tablo 3. İyileştirilmiş ölçüm modeline ilişkin dfa sonuçları

\begin{tabular}{|c|c|c|c|c|c|c|c|}
\hline Faktörler & Örtük & Standartlaştırılmış & Estimate & Standart & T değeri & $\mathbf{p}$ & Cronbach's $\alpha$ \\
\hline \multirow{8}{*}{$\begin{array}{l}\text { Toplumsal ve } \\
\text { Sosyal } \\
\text { Sorumluluk } \\
\text { (Faktör1) }\end{array}$} & Madde36 & 0,604 & 1,000 & & & & \multirow{8}{*}{0,935} \\
\hline & Madde34 & 0,538 & 0,960 & 0,086 & 11,218 & $* * *$ & \\
\hline & Madde 32 & 0,738 & 1,412 & 0,124 & 11,418 & $* * *$ & \\
\hline & Madde31 & 0,654 & 1,290 & 0,123 & 10,492 & $* * *$ & \\
\hline & Madde30 & 0,668 & 1,114 & 0,105 & 10,607 & $* * *$ & \\
\hline & Madde29 & 0,711 & 1,358 & 0,122 & 11,099 & $* * *$ & \\
\hline & Madde27 & 0,747 & 1,362 & 0,118 & 11,507 & $* * *$ & \\
\hline & Madde26 & 0,712 & 1,459 & 0,131 & 11,148 & $* * *$ & \\
\hline \multirow{6}{*}{$\begin{array}{l}\text { Toplumsal Görüş } \\
\text { ve Anlay1ş } \\
\text { (Faktör2) }\end{array}$} & Madde23 & 0,677 & 1,000 & & & & \multirow{6}{*}{0,895} \\
\hline & Madde22 & 0,756 & 1,378 & 0,105 & 13,175 & $* * *$ & \\
\hline & Madde20 & 0,790 & 1,378 & 0,101 & 13,660 & $* * *$ & \\
\hline & Madde19 & 0,709 & 1,047 & 0,084 & 12,452 & $* * *$ & \\
\hline & Madde18 & 0,620 & 0,919 & 0,083 & 11,015 & $* * *$ & \\
\hline & Madde17 & 0,601 & 0,884 & 0,082 & 10,777 & $* * *$ & \\
\hline \multirow{5}{*}{$\begin{array}{l}\text { Toplum Üzerinde } \\
\text { Etkili Kişilerin } \\
\text { Rolü (Faktör3) }\end{array}$} & Madde10 & 0,771 & 1,000 & & & & \multirow{5}{*}{0,880} \\
\hline & Madde9 & 0,826 & 1,011 & 0,062 & 16,241 & $* * *$ & \\
\hline & Madde8 & 0,777 & 1,112 & 0,073 & 15,333 & $* * *$ & \\
\hline & Madde6 & 0,623 & 1,025 & 0,085 & 12,088 & $* * *$ & \\
\hline & Madde5 & 0,546 & 0,835 & 0,080 & 10,461 & $* * *$ & \\
\hline \multirow{4}{*}{$\begin{array}{l}\text { Davranışsal } \\
\text { İnançlar (Faktör4) }\end{array}$} & Madde37 & 0,588 & 1,000 & & & & \multirow{4}{*}{0,860} \\
\hline & Madde15 & 0,687 & 1,093 & 0,099 & 11,004 & $* * *$ & \\
\hline & Madde14 & 0,935 & 1,658 & 0,127 & 13,105 & $* * *$ & \\
\hline & Madde13 & 0,859 & 1,540 & 0,121 & 12,690 & $* * *$ & \\
\hline \multirow{3}{*}{$\begin{array}{l}\text { Sağlık Açısından } \\
\text { Faydalı Olması } \\
\text { (Faktör5) }\end{array}$} & Madde3 & 0,673 & 1,000 & & & & \multirow{3}{*}{0,835} \\
\hline & Madde2 & 0,681 & 1,031 & 0,097 & 10,577 & $* * *$ & \\
\hline & Madde1 & 0,719 & 1,178 & 0,108 & 10,910 & $* * *$ & \\
\hline
\end{tabular}




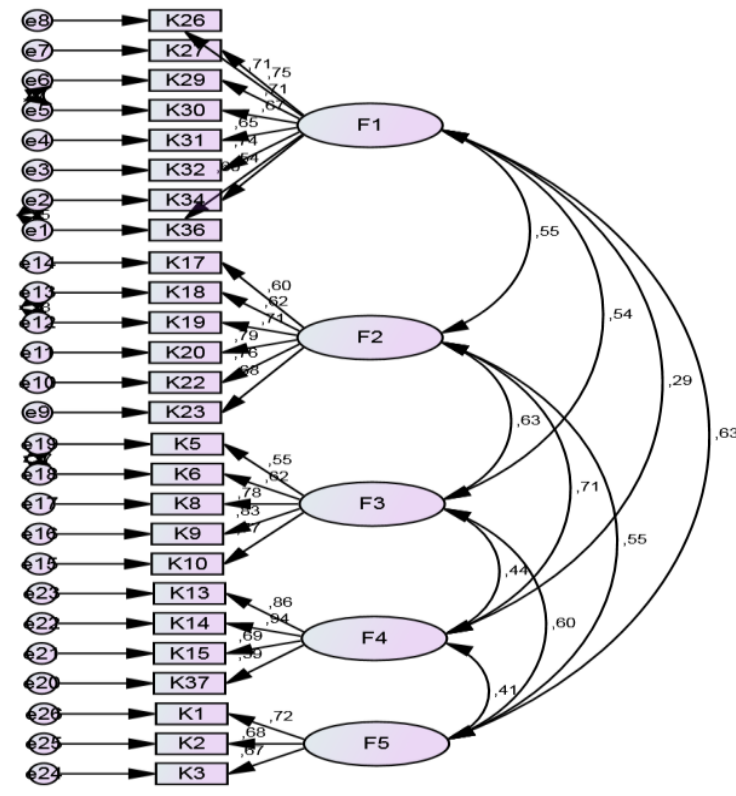

[(X2/df: 2,473; GFI: 0,87; NFI: 0,86; CFI: 0,91; RMR: 0,061; TLI: 0,90; IFI: 0,91; AGFI: 0,86)]

Şekil 1. Kan bağışında bulunmada etkili olan faktörler araştırma modeli (ölçüm modeli) ve uyum iyiliği sonuçları

Yukarıda verilen, RMR, GFI, AGFI, IFI, TLI, CFI, RMSEA, SRMR değerleri model uyumunun (model fit) sağlandığını göstermektedir. Bakılacak değerlerle ilgili bir sınırlama yoktur. Raporlanan değerler araştırmacının dikkat çekmek istediği değerlere göre değişebilmektedir. Ayrıca ölçüm modelinin geçerlilik ve güvenilirliğini belirlemek amacıyla hesaplanan faktörlerin açıklanan varyansları ve güvenilirlikleri Tablo 3'de verilmiştir.

Regresyon değerleri, gözlenen değişkenlerin, gizli değişkenleri tahmin etme gücünü, yani faktör yüklenimlerini gösterir. Yukarıdaki her ikili ilişski için "p" değerleri 0,05 'ten küçük olduğu için faktör yüklenimleri önemlidir. Faktör yüklenimlerinin önemli çıkması maddelerin, faktörlere doğru yüklendiği anlamına gelmektedir. Ayrıca standardize edilmiş regresyon katsayılarının tamamının 0,546 ve daha büyük olması gizli değişkenleri tahmin etme gücünün, yani her bir maddenin faktör yüklenimlerinin yüksek olduğunu göstermektedir. Aşağıdaki Tablo 4'te literatürde genel kabul gören iyilik uyum indeksi değerleri analiz sonrası elde edilen değerler gösterilmiştir.

Tablo 4'te görüldüğü üzere elde edilen sonuçlar, önerilen araştırma modelinin uyum indekslerinin kabul edilebilir uyum düzeyinde olduğunu göstermektedir. Açıklayıcı ve doğrulayıcı faktör analizleri ile elde edilen bulgular, modelin yapı geçerliliğinin sağlandığını göstermektedir. Açıklayıcı faktör analizi ile ortaya konulan yap1 geçerliliği, doğrulayıcı faktör analizi ile de teyit edilmiştir. Güvenilirlik katsayısı Alfa $=0,945$ olarak bulunmuştur. Tablo 3 'teki değerlere göre kan bağışını etkileyen faktörlerin belirlenmesine yönelik ölçeğinin alt boyutlarının Cronbach $\alpha$ güvenirlik katsayıları incelendiğinde bu katsayının sırasıyla "Toplumsal ve Sosyal Sorumluluk" faktörü için 0,935 olarak, "Toplumsal Görüş ve Anlayış" faktörü için 0.895 olarak,
“Toplum Üzerinde Etkili Kişilerin Rolü” faktörü için 0,880 olarak, "Davranışsal İnançlar" faktörü için 0,860 ve "Sağlık Açısından Faydalı Olması" faktörü için ise 0,835 olarak hesaplandığ 1 görülmektedir. Buna göre faktörlerin tamamının yüksek güvenirlik değerine sahip olduğu söylenebilir.

Tablo 4. Ölçüm modeli uyum iyiliği indeksleri

\begin{tabular}{|c|c|c|c|}
\hline $\begin{array}{c}\text { Genel } \\
\text { Model } \\
\text { Uyumu }\end{array}$ & İyi Uyum & $\begin{array}{c}\text { Kabul } \\
\text { Edilebilir } \\
\text { Uyum }\end{array}$ & $\begin{array}{c}\text { EIde Edilen } \\
\text { Uyum } \\
\text { Değerleri }\end{array}$ \\
\hline $\mathrm{x}^{2} / \mathrm{sd}$ & $\leq 3$ & $\leq 5$ & 2,473 \\
\hline NFI & $\geq 0,95$ & $\geq 0,90$ & 0,868 \\
\hline CFI & $\geq 0,97$ & $\geq 0,95$ & 0,917 \\
\hline IFI & $\geq 0,95$ & $0,94-0,90$ & 0,917 \\
\hline AGFI & $>0,95$ & $\geq 0,85$ & 0,861 \\
\hline GFI & $\geq 0,90$ & $0,89-0,85$ & 0,887 \\
\hline RMR & $<0,05$ & $<0,08$ & 0,061 \\
\hline
\end{tabular}

\section{TARTIŞMA}

Kan bağıșını etkileyen faktörleri ölçmeye yarayan bir ölçeğin geliştirilmesi amacıyla yapılan bu çalışma, Türkiye ölçeğinde toplum üzerinde yürütülmüştür. Araştırmadan elde edilen sonuçlar aşağıda verilmiştir: Açıklayıcı faktör analizi sonuçlarına göre; kan bağışında bulunmada etkili olan faktörler 5 farklı boyut altında toplanmıştır. $\mathrm{Bu}$ boyutlar; "toplumsal ve sosyal sorumluluk", "toplumsal görüş ve anlayış", "toplum üzerinde etkili kişilerin rolü”, “davranışsal inançlar” ve "sağlık açısından faydalı olması" şeklinde literatüre dayandırılarak isimlendirilmiştir.

Doğrulayıcı faktör analizleri yapılarak; kan bağışında bulunmada etkili olan faktörler arasındaki ilişkilerin kabul edilebilir uyum indeksine sahip olduğu görülmüştür. Tüm değişkenler için yapılan güvenilirlik analizinde, ölçeğin güvenilirlik seviyelerinin yüksek derecede olduğu tespit edilmiştir. Bunun yanı sıra önerilen araştırma modelinin uyum indekslerinin kabul edilebilir uyum düzeyinde olduğu görülmüştür. Aynı zamanda açıklayıcı ve doğrulayıcı faktör analizleri ile elde edilen bulgular, modelin yapı geçerliliğinin sağlandığını göstermiştir. Açıklayıcı faktör analizi ile ortaya konulan yapı geçerliliği, doğrulayıcı faktör analizi ile de teyit edilmiştir. Güvenilirlik katsayısı Alfa= 0,945 olarak bulunmuştur. $\mathrm{Bu}$ değer $0,80 \leq \alpha<1,00$ arasında olduğundan, ölçek yüksek derecede güvenilirdir. Dolayısıyla "kan bağışı ölçeği” için geçerlilik ve güvenilirlik sağlandığından "kan bağışı ölçeği”" kan bağışı ile ilgili beklentilerini ölçmek için rehber ölçek olarak kullanılabilir. Literatürde ağırlıklı olarak kan bağışı uygulamasının; yaş, cinsiyet, eğitim, sosyo-ekonomik durum, fedakârlık, sosyal sorumluluk, akran etkisi, sağlık iletişimine erişim, kan bağışının önemi hakkında bilgi, önceki bağışlar, aktif kan bağışçılarının etkisi gibi çeşitli faktörlerden etkilendiği vurgulanmıştır $(24,25)$. Bu 
araştırmada kan bağışı yapılmasının veya kan bağışı yapılmamasının nedenleri önceki çalışmalara benzer şekilde bulunmuştur ve daha kapsamlı bir şekilde ifade edilmiştir. Yapılan çalışmalarda genel olarak, daha sık kan bağışında bulunanların, bunu ahlaki tatmin hissettikleri için yaptıkları belirtilmiştir (26,\$̧275). Bağış yapmayanlar bağış yapmamalarının ana nedenini ise, kendilerine bu konuda başvurulmaması veya bağış yapma firsatlarının olmaması olarak belirtmiş̧lerdir (26-29).

Genç yetişkin öğrenciler arasında kan bağışı uygulamasını araştıran bir çalışma; kan bağışında bulunmaya yönelik olarak kolejlerde düzenli olarak farkındalık programları yürütmenin, öğrencileri iyi derecede bilgilendirdiği ve motive ettiği ve bunun yanı sıra bu kan verme farkındalığının, gelecekte bazı kronik hastalıkları önleyebileceğinin bilinmesi gerektiği vurgulanmıştır (8). Benzer şekilde üçüncü basamak bir hastanenin çalışanları arasında kan bağışını etkileyen faktörler üzerine yapılan bir araştırmada; bağışçı olanlar kan bağışını insani bir neden olarak gördüklerini ve bağış yapmanın manevi tatmin sağladığını vurgularken; bağışçı olmayanlar kan bağışının zayıflığa/kansızlığa yol açtığını ve vericilere göre sağlığa zararlı olduğunu düşündüklerini ifade etmişlerdir. Aynı çalışmada erkeklerin ve daha yüksek sosyo-ekonomik sınıftakilerin ağırlıklı olarak kan bağışladığg 1 görülmüştür (30).

Sonuç olarak bu çalışma, toplumun kan, kan gereksinimi ve kan bağışı konusunda neleri, ne kadar ve ne derece doğru bildiklerinin ve kan bağışı evriminin incelenmesinde daha net bir vizyonun oluşturulmasında ve düzenli ve sürdürülebilir kan bağışının sağlanabilmesinde ve kan bağışı kampanyalarının desteklenmesinde ölçülü bir katkı sağlamaktadır. Aynı zamanda bu çalışma, genel olarak kan bağışında bulunmama sebeplerine yönelik olarak yapılan çalışmalara ilaveten, bu zamana kadar daha az sayıda çalışılmış olan kan bağışında bulunmada etkili olan faktörlerin belirlenmesine yönelik yapılmış çalışmalara çeşitlilik katarak kavramsal bir düzeyde literatüre katkıda bulunmaktadır. Diğer taraftan bu çalışmanın ampirik sonuçları, kan bağışında bulunmanın belirleyicileri olarak "toplumsal ve sosyal sorumluluğun", "toplumsal görüş ve anlayışın", "toplum üzerinde etkili kişilerin rolünün”, "davranışsal inançların" ve "sağlık açısından faydalı olmasının” önemini vurgulamaktadır.

Yazar katkıları: Fikir/Kavram: F.Y., Y.K.; Tasarım: F.Y., Y.K.; Veri Toplama: F.Y.; Analiz ve Yorum: Y.K.; Literatür Taraması: F.Y.; Makale Yazımı: F.Y., Y.K.; Eleştirel İnceleme: F.Y., Y.K.

\section{KAYNAKLAR}

1. World Health Organization [Internet]. Blood safety and availability, Inc.; WHO Global Database [Updated: 2020 June 10; Cited: 2020 September 18]. Available from: https://www.who.int/.

2. Weiser TG, Regenbogen SE, Thompson KD, Haynes AB, Lipsitz SR, Berry WR, et al. An estimation of the global volume of surgery: a modelling strategy based on available data. The Lancet. 2008; 372(9633): 13944. https://doi.org/10.1016/S0140-6736(08)60878-8.

3. Olaiya MA, Ajala A, Olatunji RO. Knowledge, attitudes, beliefs and motivations towards blood donations among blood donors in Lagos, Nigeria. Transfusion Med. 2004; 14(1): 13-7. https://doi.org/10.1111/j.0958-7578.2004.00474.x.

4. Guyton AC, Hall JE. The body fluid compartments: extracellular and intracellular fluids; interstitial fluid and edema. Guyton and Hall textbook of medical physiology, 13th ed. Pennsylvania: Elsevier Saunders; 2015.

5. Kaya E, Sezek F, Doğan S. Üniversite öğrencilerinin kan bağışına karşı tutumları ve kan bağışında alan bilgilerinin etkisinin incelenmesi. Journal of Arts and Sciences. 2007; 1(7): 97-114.

6. Salonen JT, Tuomainen TP, Salonen R, Lakka TA, Nyyssönen K. Donation of blood is associated with reduced risk of myocardial infarction. The Kuopio Ischaemic Heart Disease Risk Factor Study. Am J Epidemiol. 1998; 148(5): 445-51.

7. Snelling PC. Challenging the moral status of blood donation. Health Care Analysis. 2014; 22(4): 340-65.

8. Roopadevi V, Nanjaiah R, Karinagannanavar A. Descriptive study on factors affecting blood donation among young adult students. National Journal of Community Medicine. 2017; 8(8): 487-91.

9. Glynn SA, Williams CC, Nass J, Bethel D. Attitudes toward blood donation incentives in the United States: implications for donor recruitment. Transfusion. 2003; 43(1): 7-16. https://doi.org/10.1046/j.15372995.2003.00252.x.

10. Breckler SJ. Memory for the experience of donating blood: Just how bad was it?. Basic and Applied Social Psychology. 1994; 15(4): 467-88. https://doi.org/10.1207/s15324834basp1504_5.

11. Hollingsworth B, Wildman J. What population factors influence the decision to donate blood?. Transfusion Medicine. $\quad 2004 ; \quad$ 14(1): 9-12. https://doi.org/10.1111/j.0958-7578.2004.00473.x.

12. Wiwanitkit V. Knowledge about blood donation among a sample of Thai university students. Vox Sang. $\quad 2002 ; \quad 83(2)$ : $197-9$. https://doi.org/10.1046/j.1423-0410.2002.00209.x.

13. Flegel WA, Besenfelder W, Wagner FF. Predicting a donor's likelihood of donating within a preselected time interval. Transfusion Medicine. 2000; 10(3): 181-92. https://doi.org/10.1046/j.13653148.2000.00251.x.

14. Smith A, Matthews R, Fiddler J. Recruitment and retention ofblooddonors in four Canadian cities: an analysis of the role of community and social networks. Transfusion. 2013; 53(5): 180-4. https://doi.org/10.1111/trf.12478.

15. Zaller N, Nelson KE, Ness P, Wen G, Bai X, Shan H. Knowledge, attitude and practice survey regarding blood donation in a Northwestern Chinese city. Transfusion Medicine. 2005; 15(4): 277-86.

16. Ou-Yang J, Bei CH, He B, Rong X. Factors influencing blood donation: A cross-sectional survey in Guangzhou, China. Transfusion Medicine. 2017; 27(4): 256-67.

17. Bednall TC, Bove LL. Donating blood: a metaanalytic review of self-reported motivators and deterrents. Transfusion Medicine Reviews. 2011; 25(4):

317-34. https://doi.org/10.1016/j.tmrv.2011.04.005. 
18. Ferguson E. Mechanism of altruism approach to blood donor recruitment and retention: a review and future directions. Transfusion Medicine. 2015; 25(4): 211-26. https://doi.org/10.1111/tme.12233. Epub 2015 Aug 27.

19. Chen S, Chen A, Yan Z. Analysis of factors influencing donors becoming regular (in Chinese). Chinese Journal of Blood Transfusion. 2012; 8: 7767.

20. Finck R, Ziman A, Hoffman M. Phang-Tang M. Yuan S. Motivating factors and potential deterrents to blood donation in high school aged blood donors. Journal of Blood Transfusion. 2016: 1-8. doi: 10.1155/2016/8624230.

21. Çelik C, Güven G. Kan bağışı tutum ölçeğinin geliştirilmesi: geçerlilik ve güvenilirlik çalışması. EUJEF. 2015; 17(2): 504-21.

22. Bostancı BN, Daștan M, Kıranșal N. Practices and attitudes towards blood donation in health high school students. International Journal of Human Sciences. 2013; 10(1): 293-306.

23. Alam M, Masalmeh B. Knowledge, attitudes and practices regarding blood donation among the Saudi population. Saudi Med J. 2004; 25(3): 318-21.

24. Condie S, Maxwell N. Social psychology of blood donors. Transfusion. 1970; 10(2): 79-83. https://doi.org/10.1111/j.1537-2995.1970.tb00709.x.

25. Holdershaw J, Gendall P, Wright M. Predicting willingness to donate blood. Aust Mark J. 2003; 11(1): $\quad 87-96 . \quad$ https://doi.org/10.1016/S14413582(03)70120-7.

26. Benedict N, Usimenahon A, Alexander NI, Isi A. Knowledge, attitude and practice of voluntary blood donation among physicians in a tertiary health facility of a developing country. Journal of Blood Disorders \& Transfusion. 2012; 3(1): 4-10. https://doi.org/10.5348/ijbti-2012-7-OA-2.

27. Amatya M. Study of knowledge, attitude and practice of blood donation among students of different colleges of kathmandu. Int J Pharma Biol Arch. 2013; 4(3): 424-8. https://doi.org/10.22377/IJPBA.V4I3.1003.

28. Devi S, Laishram J, Shantibala K, Elangbam V. Knowledge, attitude and practice of blood safety and donation. Indian Medical Gazette. 2012; 145(1): 1-5.

29. Dubey A, Sonker A, Chaurasia R, Chaudhary R. Knowledge, attitude and beliefs of people in North India regarding blood donation. Blood Transfus. 2014; 12(1): 21-7. https://doi.org/10.2450/2012.005812.

30. Furmeen S, Reddy S, Reddy M. Factors influencing blood donation among the workers of a tertiary care hospital, Chitradurga: a comparative study, Int J Community Med Public Health. 2018; 5(3): 1004-9. https://doi.org/10.18203/2394-6040.ijcmph20180751.

31. Mercola. Four Unexpected Benefits of Donating Blood, July 28, 2014. Available at: https://dialyguard.mesalabs.com/2014/10/14/4unexpected-benefits-of-donating-blood. Accessed on 20 March, 2021. 